\title{
Using the Multi-Theory Model (MTM) of Health Behavior Change to Explain Intentional Outdoor Nature Contact Behavior among College Students
}

\author{
Manoj Sharma ${ }^{1}$, Erin Largo-Wight ${ }^{2}$, Amar Kanekar ${ }^{3}$, Hana Kusumoto ${ }^{2}$, Stephanie Hooper ${ }^{2}$ \\ and Vinayak K. Nahar ${ }^{4,5, *}$ \\ 1 Department of Environmental \& Occupational Health, School of Public Health, University of Nevada, \\ Las Vegas, NV 89119, USA; manoj.sharma@unlv.edu \\ 2 Department of Public Health, University of North Florida, Jacksonville, FL 32224, USA; \\ largo.wight@unf.edu (E.L.-W.); hana.kusumoto@gmail.com (H.K.); stephanielynnhooper@gmail.com (S.H.) \\ 3 College of Business, Health and Human Services, University of Arkansas at Little Rock, \\ Little Rock, AR 72204, USA; axkanekar@ualr.edu \\ 4 Department of Dermatology, School of Medicine, University of Mississippi Medical Center, \\ Jackson, MS 39216, USA \\ 5 Department of Preventive Medicine, School of Medicine, University of Mississippi Medical Center, \\ Jackson, MS 39216, USA \\ * Correspondence: naharvinayak@gmail.com; Tel.: +1-(601)-495-5876
}

Received: 10 July 2020; Accepted: 19 August 2020; Published: 21 August 2020 updates

\begin{abstract}
Nature contact is an emerging health behavior and is defined as the interaction between human beings and animals, plants, natural scenic views, or outdoor activities. Studies have shown that exposure to the outdoors (as a means of contact with nature) reduces perceived stress and promotes health and wellbeing among varying populations in many settings. To date, however, there are few studies exploring the impact of nature contact among college students, especially in the United States. In addition, the determinants of nature contact behavior have not adequately been explored using behavioral theories. The purpose of this study was to use the multi-theory model (MTM) of health behavior change, a contemporary fourth-generation behavioral theory in explaining intentional outdoor nature contact behavior among college students. Using a cross-sectional design, 401 students completed the validated survey based on MTM. Of these, 281 met the inclusion criteria. The mean score for perceived stress based on the Perceived Stress Scale (PSS-10) in the sample was 21.60 (7.08) units, with a possible minimum and maximum scores ranging from 0 to 40 units. Constructs of behavioral confidence (standardized coefficient $=0.591, p<0.001$ ) and changes in the physical environment (standardized coefficient $=0.271, p<0.001$ ) from MTM accounted for $57.5 \%$ of the variance in the initiation for intentional outdoor nature contact behavior. All the three constructs of MTM-namely, emotional transformation (standardized coefficient = $0.173, p=0.021$ ), practice for change (standardized coefficient $=0.317, p<0.001$ ), and changes in the social environment (standardized coefficient $=0.204, p=0.002$ ) —were statistically significant and contributed substantively toward the variance (31.0\%) in sustenance. MTM provides a useful and pragmatic framework for designing interventions to promote intentional nature contact behavior among college students.
\end{abstract}

Keywords: perceived stress; nature contact; distress; health behavior; college students 


\section{Introduction}

Exposure to nature has been shown to improve the quality of life for all people [1]. Contact with nature has been found to positively influence outcomes in several diseases and conditions, including depression, anxiety, attention deficit hyperactivity disorder (ADHD), cardiovascular disease, Type 2 diabetes mellitus, cancer, obesity, and mobility impairment; boost immunity in some infectious diseases; aid in recovery from surgery; improve birth outcomes; and provide relief from musculoskeletal symptoms, relief from migraines, and improvement in respiratory diseases [2-5]. Such contact with nature is especially beneficial for mental health and wellbeing [6].

Studies have shown that contact with nature impacts mental health through better stress appraisal, relaxation, and stress recovery $[7,8]$, and improves overall health through boosted immune functioning as well as through other mechanisms, including environmental factors and altered behaviors [2]. Nature contact behavior is a significant predictor for nature connectedness [9]. A meta-analysis exploring the linkages of nature connectedness with happiness found that it had a statistically significant effect size $(r=0.19)$ [10]. Specifically, the relationship of nature connectedness was found between vitality $(r$ $=0.24)$, positive affect $(r=0.22)$, and satisfaction with life $(r=0.17)$. Contact with nature also fosters pro-environmental attitudes and behaviors $[9,11]$. It is clear that contact with nature has myriad valuable effects on health and wellbeing, particularly mental health and wellbeing.

However, contact with nature has been decreasing as more people live in urban areas and spend the majority of their time indoors [12]. The problem is further compounded by excessive time spent in front of a screen, a behavior that is increasing, especially among young adults [13]. Furthermore, young adults, particularly college students, experience a plethora of stressors that cause distress in their lives. Among the common stressors are those related to academic performance, including test anxiety, the pressure to succeed, relationships, and worry about plans after graduation [14]. Stress has been strongly correlated with the occurrence of mental health disorders and suicide in college students [15]. Mental health-related illnesses generally have their onset before the age of 25 years [16]. According to World Health Organization's survey from 21 countries, 20.3\% of college students had mental disorders in the past 12 months, of which anxiety disorders were most common [17].

In recent years, various interventions to reduce stress have been designed and evaluated in college students. Some of these have used web-based interventions [18,19], mobile-app based mindfulness meditation [20,21], biofeedback [22], canine play [23], deep breathing [24], vestibular stimulation using swings [25], and others. These interventions have yielded mixed results in terms of efficacy and have used very small sample sizes. Very few findings used behavioral theories and, if used, there were limitations on how constructs were operationalized. Furthermore, it is notable that few of these interventions have utilized the intentional promotion of nature contact behavior as a modality for stress management, especially in the United States. A recent scoping review found 13 studies with college students, of which 10 were from Japan, apparently by the same group of researchers. The sample sizes of these studies were very small, and the explicit use of behavioral theories in promoting exposure to nature contact behavior has not been observed [26]. The determinants of nature contact behavior and its putative role in stress management among college students need to be studied. Therefore, the purpose of this study was to utilize a contemporary fourth-generation behavioral theory in explaining intentional outdoor nature contact behavior among college students. Secondarily, the study also explores the prevalence of intentional outdoor nature contact behavior among college students at a select southeastern university and examined its linkage with perceived stress. For this study, intentional outdoor nature contact behavior was defined as an interaction between human beings and animals, plants, natural scenic views, or outdoor activities.

\section{Theoretical Framework}

The theory used in this study was the multi-theory model (MTM) of health behavior change $[27,28]$. According to this theory, behavior change is bisected into (1) initiation and (2) sustenance or maintenance. For initiation, the individual needs to be convinced that the advantages are more than the disadvantages 
(participatory dialogue), must have behavioral confidence, and must have support from the physical environment. For the maintenance of behavior change, the person must be able to transform his or her emotions into goals, continually strive for change (practice for change), and must have support from their social environment. The theory has been used in cross-sectional designs with a variety of health behaviors [29-37] and in experimental designs with physical activity [38], fruit and vegetable consumption [39], and water pipe cessation [40], with encouraging results. This was the first study using MTM with intentional outdoor nature contact behavior.

\section{Methods}

\subsection{Study Design}

A cross-sectional study design was used for this study. The independent variables in this design were the constructs of the multi-theory model (MTM) of health behavior change for each of the two models: initiation and sustenance. For the initiation model, the dependent variable was the intent for practicing intentional outdoor nature contact for $20 \mathrm{~min}$ daily in the upcoming week. For the sustenance model, the dependent variable was the intent for practicing intentional outdoor nature contact for $20 \mathrm{~min}$ daily for the next five years. The rationale for choosing the dose of $20 \mathrm{~min}$ for this study seems justified based on the findings of a scoping review [26].

\subsection{Population and Sample}

The target population for this study was undergraduate students. The study sample was recruited at a southeastern university in the United States. The participants from the target population for this study (3494 undergraduate college students) were identified and recruited via the University Institutional Research Office. The number of participants to be recruited for this study was based on a power analysis using $G^{*}$ Power [41]. In calculating the sample size, the alpha was set as 0.05 and the power at 0.80 , the number of predictors in each model was three, and the effect size was estimated to be 0.05 (small). These assumptions yielded a quota sample size of 222, which was considered sufficient for this study. An online survey was sent via an online survey tool along with two reminder survey invitations to the student pool. The quota sample size was met at the end of the second reminder. Respondents that met the following eligibility criteria were included: (1) aged 18 years or older; (2) during the past $24 \mathrm{~h}$, they did not engage in intentional outdoor nature contact for stress reduction; and (3) over the past 7 days, they practiced less than $20 \mathrm{~min}$ of intentional outdoor nature contact for stress reduction on average each day.

\subsection{Instrumentation}

For this study, nature contact was defined as the interaction between human beings and animals, plants, natural scenic views, and outdoor activities. Specifically, intentional outdoor nature contact was reified and was defined as spending time outdoors to reduce stress. This could be either active (walking) or passive (sitting), but both active and passive behavior involved noticing natural surroundings and was to be performed for stress reduction. The instrument (with scoring) for this study was designed to assess intentional outdoor nature contact using the constructs of multi-theory model (MTM) of health behavior change. The instrument consisted of a total of 48 items and was validated by a panel of six experts in two rounds for face and content validity. There were 9 items capturing the participant demographics and 10 items based on the "Perceived Stress Scale (PSS-10)" [42], which was rated on a 5-point scale from never (0) to almost never (1), sometimes (2), fairly often (3), and very often (4). Four items were reverse coded. After they were scored, the scores of each item were summed and the possible minimum and maximum scores ranged from 0 to 40 units.

Constitutively, the first construct in MTM is participatory dialogue, and this defined as convincing the participants about the possible advantages of behavior change exceeding the possible disadvantages $[27,28]$. Operationally, six items measured the "advantages of the participatory dialogue" 
construct (e.g., be healthier, be happier, not feel tired, etc.), and six items measured the "disadvantages of the participatory dialogue" construct (e.g., having less time for other things, finding it boring, finding it useless, etc.). The items were rated on a 5-point scale from never (0) to almost never (1), sometimes (2), fairly often (3), and very often (4). The score of participatory dialogue construct was obtained by subtracting the score of disadvantages from the advantages score (possible minimum and maximum scores ranged from -24 to +24 units). Constitutively, the second construct in MTM is behavioral confidence, which is defined as the futuristic confidence in an individual to make a behavior change that can have an internal or an external source $[27,28]$. Operationally, five items assessed the "behavioral confidence" construct (e.g., being able to start $20 \mathrm{~min}$ of intentional outdoor nature contact behavior daily, despite other duties, despite being busy, etc.) on a scale of not at all sure (0), slightly sure (1), moderately sure (2), very sure (3), completely sure (4), with possible minimum and maximum scores ranging from 0 to 20 units. Constitutively, the third construct in MTM is changes in the physical environment, which are defined as making modifications related to the availability and accessibility of resources that help in the initiation of the behavior change $[27,28]$ Operationally, there were three items (finding a place, eliminating distractions, having necessary resources) on a scale of not at all sure (0), slightly sure (1), moderately sure (2), very sure (3), completely sure (4), with possible minimum and maximum scores ranging from 0 to 12 units that assessed the construct of "changes in the physical environment."

The fourth construct in MTM is the emotional transformation that entails converting emotions or feelings toward the goal of maintaining behavior change $\{27,28]$. Operationally, three items (setting emotions to goals, self-motivation, and overcoming self-doubt) assessed the "emotional transformation" construct on a scale of not at all sure (0), slightly sure (1), moderately sure (2), very sure (3), completely sure (4), with possible minimum and maximum scores ranging from 0 to 12 units. The fifth construct in MTM is the practice for change, which entails constantly thinking about the behavior change and making mid-course rectifications to one's strategy, overcoming barriers, and remaining focused on the behavior change to maintain behavior change $[27,28]$. Operationally, three items (keeping a self-diary/journal, overcoming barriers, and ability to change plans) measured the "practice for change" construct on a scale of not at all sure (0), slightly sure (1), moderately sure (2), very sure (3), completely sure (4), with possible minimum and maximum scores ranging from 0 to 12 units. The sixth construct in MTM is the change in the social environment, which is defined as developing social support from the environment to help with the maintenance of behavior change [26,27]. Operationally, three items (support from family, friends, and health professionals) assessed the construct of "changes in the social environment" on a scale of not at all sure (0), slightly sure (1), moderately sure (2), very sure (3), completely sure (4), with possible minimum and maximum scores ranging from 0 to 12 units.

Finally, practicing intentional outdoor nature contact for $20 \mathrm{~min}$ daily in the upcoming week (initiation) and practicing intentional outdoor nature contact for 20 min daily for the next five years (sustenance) were measured on a scale of not at all likely (0), somewhat likely (1), moderately likely (2), very likely (3), and completely likely (4). For internal consistency, Cronbach's alphas were calculated for all subscales and the entire scale (which was constituted of all subscales), and a confirmatory factor analysis was performed for construct validation.

\subsection{Ethical Approval}

The approval for this study was obtained from the Institutional Review Board (IRB) at the university. Data were collected only after IRB approval (approved by University of North Florida IRB under Protocol \# 1218633-2). A statement in the online survey tool, directions indicating the nature of participation as voluntary, having no direct benefits, and the maintenance of confidentiality by researchers served as informed consent for completing the survey. 


\subsection{Data Analyses}

Data were analyzed for descriptive and inferential statistics using SPSS version 25 . For descriptive statistics, frequencies and percentages were calculated for all the demographics and study variables that were categorical. Means and standard deviations were reported for those variables that were continuous. To establish the internal consistency of the scale, Cronbach's alphas were calculated for each subscale and the entire scale. For construct validation of the scale, a confirmatory factor analysis using the maximum likelihood method was employed. Stepwise multiple regression modeling was performed for both the initiation model consisting of participatory dialogue, behavioral confidence, and changes in the physical environment as predictors; and for the sustenance model with emotional transformation, practice for change, and changes in the social environment as predictors.

\section{Results}

A total of 401 students consented to participate in this study, of which 257 (64.1\%) reported that during the past $24 \mathrm{~h}$, they did not engage in intentional outdoor nature contact for stress reduction. Of 401 respondents, 281 (70.1\%) reported that over the past 7 days, they practiced less than 20 min of intentional outdoor nature contact for stress reduction on average each day and were included as participants, which satisfied the sample size requirement for the current study.

The mean age of the study participants was $21.69( \pm 6.39)$ years. About $60 \%$ were female, $58 \%$ were White or Caucasian American, 6.8\% had completed college or had a graduate degree, and $56.9 \%$ reported working for pay. Regarding the current financial situation, $50.2 \%$ indicated having enough money to pay their bills. Detailed results of the socio-demographic characteristics of the study participants are depicted in Table 1.

Table 1. Socio-demographic characteristics of the participants $(n=281)$.

\begin{tabular}{lcc}
\hline \multicolumn{1}{c}{ Characteristic } & Mean (SD) & $n \mathbf{( \% )}$ \\
\hline Age (years) & $21.69( \pm 6.39)$ & \\
\hline Gender & \\
\hline Male & $82(29.2 \%)$ \\
\hline Female & $167(59.4 \%)$ \\
\hline Other & $6(2.1 \%)$ \\
\hline Race/Ethnicity & $163(58.0 \%)$ \\
\hline White or Caucasian American & $32(11.4 \%)$ \\
\hline Black or African American & $18(6.4 \%)$ \\
\hline Asian American & $2(0.7 \%)$ \\
\hline American Indian & $24(8.5 \%)$ \\
\hline Hispanic American & $15(5.3 \%)$ \\
\hline Other & \\
\hline Education & $1(0.4 \%)$ \\
\hline Some schooling but not completed high school & $27(9.6 \%)$ \\
\hline Completed high school or GED & $206(73.3 \%)$ \\
\hline Some college & $19(6.8 \%)$ \\
\hline Completed college/graduate degree & $2(0.7 \%)$ \\
\hline Postgraduate degree &
\end{tabular}


Table 1. Cont.

\begin{tabular}{|c|c|c|}
\hline Characteristic & Mean (SD) & $n(\%)$ \\
\hline \multicolumn{3}{|l|}{ Work Status } \\
\hline Yes & & $160(56.9 \%)$ \\
\hline No & & $94(33.5 \%)$ \\
\hline \multicolumn{3}{|l|}{ Current Financial Situation } \\
\hline $\begin{array}{l}\text { I do not have enough money to pay my bills each } \\
\text { month }\end{array}$ & & $44(15.7 \%)$ \\
\hline I have enough money to pay my bills & & $141(50.2 \%)$ \\
\hline $\begin{array}{l}\text { I have enough money to pay my bills and some left } \\
\text { over }\end{array}$ & & $64(22.8 \%)$ \\
\hline \multicolumn{3}{|l|}{$\begin{array}{l}\text { Current situation (If you were to receive an } \\
\text { unexpected } \$ 500 \text { medical bill, would you ... ) }\end{array}$} \\
\hline Be able to pay the bill with no problem & & $73(26.0 \%)$ \\
\hline Be able to pay the bill on a monthly basis & & $114(40.6 \%)$ \\
\hline Not be able to pay the bill & & $65(23.1 \%)$ \\
\hline
\end{tabular}

Note: The characteristic categories are bolded for clarity. Due to missing data, the percentage of participants in each category of sociodemographic characteristics do not sum to $100 \%$.

The mean score for perceived stress was 21.60 (SD: \pm 7.08 , possible minimum and maximum scores ranging from 0 to 40 ). Perceived stress was not statistically significantly correlated with the initiation and sustenance of practicing intentional outdoor nature contact. The mean for the initiation of practicing intentional outdoor nature contact for $20 \mathrm{~min}$ daily in the upcoming week was 1.07 (SD: \pm 1.19 , with possible minimum and maximum scores ranging from 0 to 4 ). The mean for the sustenance of practicing intentional outdoor nature contact for daily for the next five years was 0.95 (SD: \pm 1.10 , with possible minimum and maximum scores ranging from 0 to 4). Additional descriptive statistics of MTM constructs are depicted in Table 2. As can be seen from Table 2, all the scales and subscales had Cronbach's alphas higher than 0.70 , indicating they were acceptable [43]. The construct validation also yielded one-factor solutions for each subscale, with Eigenvalues over 1.0 and factor loadings over 0.32 .

Table 2. Descriptive statistics of perceived stress and constructs of multi-theory model (MTM) of health behavior change $(n=281)$.

\begin{tabular}{ccccc}
\hline Constructs & $\begin{array}{c}\text { Possible Min. } \\
\text { \& Max. }\end{array}$ & $\begin{array}{c}\text { Observed } \\
\text { Min. \& Max. }\end{array}$ & Mean (SD) & $\begin{array}{c}\text { Cronbach's } \\
\text { Alpha }\end{array}$ \\
\hline Perceived Stress & $0-40$ & $4-38$ & $21.60( \pm 7.08)$ & 0.88 \\
\hline Initiation & $0-4$ & $0-4$ & $1.07( \pm 1.19)$ & - \\
\hline $\begin{array}{c}\text { Participatory dialogue: } \\
\text { advantages }\end{array}$ & $0-24$ & $0-24$ & $15.07( \pm 4.84)$ & 0.89 \\
\hline $\begin{array}{c}\text { Participatory dialogue: } \\
\text { disadvantages }\end{array}$ & $0-24$ & $0-24$ & $11.20( \pm 4.90)$ & 0.84 \\
\hline $\begin{array}{c}\text { Participatory dialogue: } \\
\text { advantages/disadvantages score }\end{array}$ & $-24-+24$ & $-19-+24$ & $3.92( \pm 8.67)$ & - \\
\hline Behavioral confidence & $0-20$ & $0-20$ & $3.80( \pm 4.53)$ & 0.92 \\
\hline $\begin{array}{c}\text { Changes in the physical } \\
\text { environment }\end{array}$ & $0-12$ & $0-12$ & $5.23( \pm 3.64)$ & 0.87 \\
\hline
\end{tabular}


Table 2. Cont.

\begin{tabular}{ccccc}
\hline Constructs & $\begin{array}{c}\text { Possible Min. } \\
\text { \& Max. }\end{array}$ & $\begin{array}{c}\text { Observed } \\
\text { Min. \& Max. }\end{array}$ & Mean (SD) & $\begin{array}{c}\text { Cronbach's } \\
\text { Alpha }\end{array}$ \\
\hline $\begin{array}{c}\text { Entire initiation scale (advantages, } \\
\text { disadvantages, behavioral } \\
\text { confidence, and changes in } \\
\text { the physical environment) }\end{array}$ & - & - & 0.68 \\
\hline Sustenance & $0-4$ & $0-4$ & $0.95( \pm 1.10)$ & - \\
\hline Emotional transformation & $0-12$ & $0-12$ & $4.17( \pm 3.23)$ & 0.90 \\
\hline Practice for change & $0-12$ & $0-12$ & $2.63( \pm 2.85)$ & 0.81 \\
\hline $\begin{array}{c}\text { Changes in the social environment } \\
\text { Entire sustenance scale (emotional } \\
\text { transformation, practice for } \\
\text { change, changes in the social } \\
\text { environment) }\end{array}$ & $0-12$ & $0-12$ & $3.99( \pm 3.29)$ & 0.76 \\
\hline Entire scale & - & - & - & 0.87 \\
\hline
\end{tabular}

The results of the correlations and stepwise multiple regression for the initiation model are depicted in Tables 3 and 4, respectively. The variance inflation factor (VIF) values were less than 10, indicating no multicollinearity in the regression analysis [44]. The model explained $57.5 \%$ of the variance in the initiation of intentional outdoor nature contact, $F(2,205)=140.864, p<0.001$, adjusted $R^{2}=0.575$. Behavioral confidence (standardized coefficient $=0.591, p<0.001$ ) and changes in the physical environment (standardized coefficient $=0.271, p<0.001$ ) statistically significantly predicted the initiation of intentional outdoor nature contact behavior.

Table 3. Correlation matrix of the initiation model constructs.

\begin{tabular}{ccccc}
\hline Construct & $\mathbf{1}$ & $\mathbf{2}$ & $\mathbf{3}$ & $\mathbf{4}$ \\
\hline 1. Initiation & - & $0.470^{* *}$ & $0.695^{* *}$ & $0.570^{* *}$ \\
2. Participatory dialogue: advantages/disadvantages score & & - & $0.473^{* *}$ & $0.414^{* *}$ \\
3. Behavioral confidence & & & - & $0.488^{* *}$ \\
4. Changes in the physical environment & & & & - \\
\hline
\end{tabular}

** Correlation is significant at the 0.01 level.

Table 4. Stepwise multiple regression predicting initiation for intentional outdoor nature contact $(n=281)$.

\begin{tabular}{cccccc}
\hline Variables & $\boldsymbol{B}$ & $\boldsymbol{S} \boldsymbol{E}_{\boldsymbol{B}}$ & $\boldsymbol{\beta}$ & $\boldsymbol{p}$-Value & $\mathbf{9 5 \%} \boldsymbol{C I}$ \\
\hline Behavioral confidence & 0.156 & 0.014 & 0.591 & $<0.001$ & $0.129,0.182$ \\
\hline Changes in the physical environment & 0.089 & 0.017 & 0.271 & $<0.001$ & $0.056,0.123$ \\
\hline $\mathrm{F}(2,205)=140.864, p<0.001, \mathrm{R}^{2}=0.579$, adjusted $\mathrm{R}^{2}=0.575$.
\end{tabular}

The dependent variable is the initiation of intentional outdoor nature contact; the independent variables are behavioral confidence and changes in the physical environment; $B=$ unstandardized coefficient; $S E_{B}=$ standard error of the coefficient; $\beta=$ standardized coefficient; $p=$ level of significance; $C I=$ confidence interval; participatory dialogue (advantages/disadvantages) was excluded from the model (probability of $\mathrm{F}$ to remove $\geq 0.1$ ).

The results of the correlations and stepwise multiple regression for the sustenance model are depicted in Tables 5 and 6, respectively. The VIF values were less than 10, indicating no multicollinearity 
in the regression analysis [44]. The model explained $31.0 \%$ of the variance in the sustenance of intentional outdoor nature contact, $F(3,214)=33.427, p<0.001$, adjusted $R^{2}=0.310$. Emotional transformation (standardized coefficient $=0.173, p=0.021$ ), practice for change (standardized coefficient $=0.317, p<$ 0.001 ), and changes in the social environment (standardized coefficient $=0.204, p=0.002$ ) statistically significantly predicted the sustenance of intentional outdoor nature contact behavior.

Table 5. Correlation matrix of the sustenance model constructs.

\begin{tabular}{lcccc}
\hline Construct & $\mathbf{1}$ & $\mathbf{2}$ & $\mathbf{3}$ & $\mathbf{4}$ \\
\hline 1. Sustenance & - & $0.450^{* *}$ & $0.480^{* *}$ & $0.396^{* *}$ \\
2. Emotional Transformation & & - & $0.603^{* *}$ & $0.451^{* *}$ \\
3. Practice for Change & & & - & $0.376^{* *}$ \\
4. Changes in the Social Environment & & & & - \\
\hline
\end{tabular}

** Correlation is significant at the 0.01 level.

Table 6. Stepwise multiple regression predicting the sustenance of intentional outdoor nature contact $(n=281)$.

\begin{tabular}{lccccc}
\hline Variables & $\boldsymbol{B}$ & $\boldsymbol{S} \boldsymbol{E}_{\boldsymbol{B}}$ & $\boldsymbol{\beta}$ & $\boldsymbol{p}$-Value & $\mathbf{9 5 \%} \boldsymbol{C I}$ \\
\hline Emotional Transformation & 0.059 & 0.025 & 0.173 & 0.021 & $0.009,0.108$ \\
\hline Practice for Change & 0.124 & 0.028 & 0.317 & $<0.001$ & $0.069,0.179$ \\
\hline Changes in the Social Environment & 0.068 & 0.021 & 0.204 & 0.002 & $0.026,0.110$ \\
\hline \multicolumn{5}{r}{$(3,214)=33.427, p<0.001, \mathrm{R}^{2}=0.319$, adjusted $\mathrm{R}^{2}=0.310}$.
\end{tabular}

The dependent variable is the sustenance of intentional outdoor nature contact; the independent variables are emotional transformation, practice for change, and changes in the social environment; $B$ $=$ unstandardized coefficient; $S E_{B}=$ standard error of the coefficient; $\beta=$ standardized coefficient; $p=$ level of significance; $C I=$ confidence interval.

\section{Discussion}

The purpose of this study was to identify the determinants of intentional outdoor nature contact behavior utilizing the tenets of the multi-theory model (MTM) of health behavior change. Based on the study, it was found that behavioral confidence $(p<0.001)$ and changes in the physical environment $(p<0.001)$ were statistically significant explanatory constructs for the initiation of intentional outdoor nature contact behavior among college students and together accounted for a substantial proportion of variance $(57.5 \%)$. In behavioral and social sciences, such magnitude is of practical significance. Behavioral confidence [30-37] and changes in the physical environment [31,35-37] have been found to be significant and substantial predictors of other health behaviors in several studies based on MTM with US college students. Participatory dialogue was not found to contribute to initiating intentional outdoor nature contact behavior. One possible explanation of this finding could be because the mean score for participatory dialogue was 3.92 (8.67) units, with possible minimum and maximum scores ranging from -24 to +24 units. While it was positive, it was still very low and, in the absence of an intervention, it probably did not reach the threshold to have any influence on intentional outdoor nature contact behavior. It could also be that college students were not convinced that this is a beneficial behavior and thus this construct did not account for a significant contribution to the dependent variable.

In this study, for maintaining intentional outdoor nature contact behavior, all the three constructs of MTM-namely, emotional transformation $(p=0.021)$, practice for change $(p<0.001)$, and changes in the social environment $(p=0.002)$-were statistically significant and contributed substantively toward the variance $(31.0 \%)$. Emotional transformation [30-35,37], practice for change [30,31,35-37], 
and changes in the social environment $[30,31,34,37]$ have been found to be significant and substantial predictors of other health behaviors in several studies based on MTM with US college students.

As part of its secondary purpose, this study found that a large proportion of college students $(64.1 \%)$ did not engage in intentional outdoor nature contact for stress reduction in the past $24 \mathrm{~h}$. Further, $70.1 \%$ reported that over the past 7 days they had practiced less than 20 min of intentional outdoor nature contact for stress reduction on average each day. These findings are especially relevant, since the mean score for perceived stress was 21.60 (7.08) units on a scale of 0-40 units, or slightly above the mid-point. The data were collected in the month of October, and thus the stress due to examinations would perhaps not have played an important role and could be indicative of the general levels of stress experienced by college students. College students experience stress due to relationships, studies, daily hassles, boredom (or nonevents), work, and other such stressors [45]. When stress levels are high, the role of stress management programs becomes particularly valuable. Experimentation with theory-based health promotion interventions that promote intentional outdoor nature contact behavior among college students must be carried out. MTM provides a practical and useful framework for designing such interventions.

The findings of this study have important implications for designing MTM-based health promotion interventions that promote intentional outdoor nature contact behavior among college students. The advantage of using MTM is that it can deliver brief and precise interventions and can be easily linked to technological advancements, a trend that is emerging in the field of health promotion. The term precise intervention refers to the focused delivery of messages based on the significant and proven constructs of MTM which emphasize salient aspects of behavior change. In order to build behavioral confidence, the program can utilize mobile phone apps that provide cues for the initiation of intentional outdoor nature contact behavior. The program can provide small steps for indulging in this behavior that can lead to mastery of the skills pertaining to the appreciation of nature while walking (active) or sitting (passive). This can help reduce the stress associated with daily stressors. For building the construct of changes in the physical environment, the health promotion strategies of cultivating land for nature appreciation, developing healing gardens, providing green space (parks, gardens, etc.) in communities, and advocating for the preservation of wilderness are some strategies that can go a long way [4]. For example, Cornell University has developed a "Nature Prescription Program", whereby the university community works to enhance the natural beauty of their campus so that it positively impacts every member [46].

For developing the construct of emotional transformation, the participants in the health promotion program must be taught techniques to convert their feelings into goals. For example, students when feeling frustrated or angry instead of indulging in that feeling they can make a goal to take a stroll in the park and admire nature. Not only will that help them get diverted from negative feelings, but it will enable them to relax and manage stress effectively. For influencing the construct of practice for change one must constantly be thinking and reminding oneself of the goal to engage in the behavior of intentional outdoor nature contact. Once again, technology can help this process. The use of text messaging reminders or mobile phone apps can be helpful. Finally, for modifying the construct of changes in the social environment, the program personnel can mobilize either natural (such as through friends, peers, and family) or artificial (such as through health professionals or researchers) social support.

\section{Limitations of the Study}

The study had some limitations. First, the study used a cross-sectional design, which is a snapshot in time. The weakness of this design is the lack of ability to establish a temporal relationship, which, though vital for causal inference [47], has been recently debated [48]. We chose this study design for practical reasons and future studies can use more robust longitudinal designs. Second, the study relied on self-reports which can lead to measurement error in the form of dishonest responses, bias, exaggeration, etc. While attitudinal variables can only be measured through self-report, the actual 
performance of the behavior can be objectively observed but is usually not feasible as was the case in this study. Future studies must attempt to measure actual behavior objectively. Third, the study used intentional outdoor nature contact behavior for both initiation and sustenance models which is only a proxy of the actual behavior. Finally, the study did not establish the test-retest (stability) reliability of the instrument used. This was due to lack of adequate resources. Future studies must attempt to do that.

\section{Conclusions}

Intentional outdoor nature contact behavior is an untapped stress alleviator that can be leveraged in stress management programs for college students. The contemporary, fourth-generation multi-theory model (MTM) of health behavior change provides a useful and pragmatic framework for designing such interventions. The findings of this study lend credence to the hypothesis that the constructs of this model are significant and contribute to a substantial proportion in explaining the variance in the intentional outdoor nature contact behavior. Future research must operationalize MTM in designing and evaluating health promotion interventions that promote intentional outdoor nature contact behavior.

Author Contributions: M.S., E.L.-W., A.K., and V.K.N. contributed to study conceptualization and design; M.S. developed the instrument; E.L.-W., H.K., and S.H. contributed to data collection; V.K.N. contributed to data analysis; all the authors are responsible for data interpretation; all the authors drafted the article or revised it critically for important intellectual content; all the authors gave final approval of the version of the article to be published; all the authors agree to be accountable for all aspects of the work in ensuring that questions related to the accuracy or integrity of any part of the work are appropriately investigated and resolved. All authors have read and agreed to the published version of the manuscript.

Funding: This research received no external funding.

Acknowledgments: We would like to thank all those who voluntarily participated in this research study.

Conflicts of Interest: The authors declare no conflict of interest.

Data Availability: The datasets used and/or analyzed during the current study are available from the corresponding author on reasonable request.

\section{References}

1. Díaz, S.; Pascual, U.; Stenseke, M.; Martin-López, B.; Watson, R.T.; Molnár, Z.; Hill, R.; Chan, K.M.A.; Baste, I.A.; Brauman, K.A.; et al. Assessing nature's contributions to people. Science 2018, 359, $270-272$. [CrossRef] [PubMed]

2. Kuo, M. How might contact with nature promote human health? promising mechanisms and a possible central pathway. Front. Psychol. 2015, 6, 1093. [CrossRef] [PubMed]

3. Largo-Wight, E. Cultivating healthy places and communities: Evidenced-based nature contact recommendations. Int. J. Environ. Health Res. 2011, 21, 41-61. [CrossRef] [PubMed]

4. Ray, H.; Jakubec, S.L. Nature-based experiences and health of cancer survivors. Complement. Ther. Clin. Pract. 2014, 20, 188-192. [CrossRef] [PubMed]

5. Zhang, G.; Poulsen, D.V.; Lygum, V.L.; Corazon, S.S.; Gramkow, M.C.; Stigsdotter, U.K. Health-Promoting nature access for people with mobility impairments: A systematic review. Int. J. Environ. Res. Public Health 2017, 14, 703. [CrossRef] [PubMed]

6. Bratman, G.N.; Anderson, C.B.; Berman, M.G.; Cochran, B.; De Vries, S.; Flanders, J.; Folke, C.; Frumkin, H.; Gross, J.J.; Hartig, T.; et al. Nature and mental health: An ecosystem service perspective. Sci. Adv. 2019, 5. [CrossRef]

7. Jo, H.; Song, C.; Miyazaki, Y. Physiological benefits of viewing nature: A systematic review of indoor experiments. Int. J. Environ. Res. Public Health 2019, 16, 4739. [CrossRef]

8. Largo-Wight, E.; Chen, W.W.; Dodd, V.; Weiler, R. The nature contact questionnaire: A measure of healthy workplace exposure. Work 2011, 40, 411-423. [CrossRef]

9. Lumber, R.; Richardson, M.; Sheffield, D. Beyond knowing nature: Contact, emotion, compassion, meaning, and beauty are pathways to nature connection. PLoS ONE 2017, 12, e0177186. [CrossRef] 
10. Capaldi, C.A.; Dopko, R.L.; Zelenski, J.M. The relationship between nature connectedness and happiness: A meta-analysis. Front. Psychol. 2014, 5, 976. [CrossRef]

11. Sandifer, P.A.; Sutton-Grier, A.E.; Ward, B.P. Exploring connections among nature, biodiversity, ecosystem services, and human health and well-being: Opportunities to enhance health and biodiversity conservation. Ecosyst. Serv. 2015, 12, 1-15. [CrossRef]

12. Frumkin, H.; Bratman, G.N.; Breslow, S.J.; Cochran, B.; Kahn, P.H., Jr.; Lawler, J.J.; Levin, P.S.; Tandon, P.S.; Varanasi, U.; Wolf, K.L.; et al. Nature contact and human health: A research agenda. Environ. Health Perspect. 2017, 125, 075001. [CrossRef] [PubMed]

13. Vizcaino, M.; Buman, M.; Desroches, C.T.; Wharton, C. Reliability of a new measure to assess modern screen time in adults. BMC Public Health 2019, 19, 1386. [CrossRef] [PubMed]

14. Beiter, R.; Nash, R.; McCrady, M.; Rhoades, D.; Linscomb, M.; Clarahan, M.; Sammut, S. The prevalence and correlates of depression, anxiety, and stress in a sample of college students. J. Affect. Disord. 2015, 173, 90-96. [CrossRef] [PubMed]

15. Liu, C.H.; Stevens, C.; Wong, S.H.M.; Yasui, M.; Chen, J.A. The prevalence and predictors of mental health diagnoses and suicide among U.S. college students: Implications for addressing disparities in service use. Depress. Anxiety 2019, 36, 8-17. [CrossRef]

16. Pedrelli, P.; Nyer, M.; Yeung, A.; Zulauf, C.; Wilens, T. College students: Mental health problems and treatment considerations. Acad. Psychiatry 2015, 39, 503-511. [CrossRef]

17. Auerbach, R.P.; Alonso, J.; Axinn, W.G.; Cuijpers, P.; Ebert, D.D.; Green, J.G.; Hwang, I.; Kessler, R.C.; Liu, H.; Mortier, P.; et al. Mental disorders among college students in the World Health Organization World Mental Health Surveys. Psychol. Med. 2016, 46, 2955-2970. [CrossRef]

18. Coudray, C.; Palmer, R.; Frazier, P. Moderators of the efficacy of a web-based stress management intervention for college students. J. Couns. Psychol. 2019, 66, 747-754. [CrossRef]

19. Harrer, M.; Adam, S.H.; Fleischmann, R.J.; Baumeister, H.; Auerbach, R.; Bruffaerts, R.; Cuijpers, P.; Kessler, R.C.; Berking, M.; Lehr, D.; et al. Effectiveness of an internet- and app-based intervention for college students with elevated stress: Randomized controlled trial. J. Med. Internet Res. 2018, 20, e136. [CrossRef]

20. Huberty, J.; Green, J.; Glissmann, C.; Larkey, L.; Puzia, M.; Lee, C. Efficacy of the mindfulness meditation mobile app "calm" to reduce stress among college students: Randomized controlled trial. JMIR Mhealth Uhealth 2019, 7, e14273. [CrossRef]

21. Yang, E.; Schamber, E.; Meyer, R.M.L.; Gold, J.I. Happier healers: Randomized controlled trial of mobile mindfulness for stress management. J. Altern. Complement. Med. 2018, 24, 505-513. [CrossRef] [PubMed]

22. Ratanasiripong, P.; Park, J.F.; Ratanasiripong, N.; Kathalae, D. Stress and anxiety management in nursing students: Biofeedback and mindfulness meditation. J. Nurs. Educ. 2015, 54, 520-524. [CrossRef] [PubMed]

23. Delgado, C.; Toukonen, M.; Wheeler, C. Effect of canine play interventions as a stress reduction strategy in college students. Nurse Educ. 2018, 43, 149-153. [CrossRef] [PubMed]

24. Joshi, A.; Kiran, R.; Singla, H.K.; Sah, A.N. Stress management through regulation of blood pressure among college students. Work 2016, 54, 745-752. [CrossRef] [PubMed]

25. Kumar, S.S.; Rajagopalan, A.; Mukkadan, J.K. Vestibular stimulation for stress management in students. J. Clin. Diagn. Res. 2016, 10, CC27-CC31. [CrossRef]

26. Meredith, G.R.; Rakow, D.A.; Eldermire, E.R.; Madsen, C.G.; Shelley, S.P.; Sachs, N.A. Minimum Time Dose in Nature to Positively Impact the Mental Health of College-Aged Students, and How to Measure It: A Scoping Review. Front. Psychol. 2020, 10, 2942. [CrossRef]

27. Sharma, M. Multi-theory model (MTM) for health behavior change. WebmedCentral Behav. 2015, 6, WMC004982. Available online: https://www.webmedcentral.com/article_view/4982 (accessed on 3 August 2020).

28. Sharma, M. Theoretical Foundations of Health Education and Health Promotion, 3rd ed.; Jones and Bartlett: Burlington, MA, USA, 2017; pp. 250-262.

29. Dokun-Mowete, C.A.; Sharma, M.; Beatty, F. Using multi-theory model to predict low salt intake among Nigerian adults with hypertension. Int. Q. Community Health Educ. 2019, 39, 245-255. [CrossRef]

30. Knowlden, A.P.; Sharma, M.; Nahar, V.K. Using multitheory model of health behavior change to predict adequate sleep behavior. Fam. Community Health 2017, 40, 56-61. [CrossRef] 
31. Nahar, V.K.; Sharma, M.; Catalano, H.P.; Ickes, M.J.; Johnson, P.; Ford, M.A. Testing multi-theory model (MTM) in predicting initiation and sustenance of physical activity behavior among college students. Health Promot. Perspect. 2016, 6, 58-65. [CrossRef]

32. Nahar, V.K.; Wilkerson, A.H.; Patel, F.C.; Kim, R.W.; Stephens, P.M.; Sharma, M. Utilizing Multi-Theory Model in Determining Intentions to Smoking Cessation Among Smokers. Tob. Use Insights 2019, 12. [CrossRef] [PubMed]

33. Nahar, V.K.; Wells, J.K.; Davis, R.E.; Johnson, E.C.; Johnson, J.W.; Sharma, M. Factors associated with initiation and sustenance of stress management behaviors in veterinary students: Testing of multi-theory model (MTM). Int. J. Environ. Health Res. 2020, 17, 631. [CrossRef] [PubMed]

34. Sharma, M.; Catalano, H.P.; Nahar, V.K.; Lingam, V.; Johnson, P.; Ford, M.A. Using multi-theory model of health behavior change to predict portion size consumption among college students. Health Promot. Perspect. 2016, 6, 137-144. [CrossRef] [PubMed]

35. Sharma, M.; Catalano, H.P.; Nahar, V.K.; Lingam, V.; Johnson, P.; Ford, M.A. Using multi-theory model (MTM) of health behavior change to predict water consumption instead of sugar sweetened beverages. J. Res. Health Sci. 2017, 17, 370.

36. Sharma, M.; Anyimukwu, C.; Kim, R.W.; Nahar, V.K.; Ford, M.A. Predictors of responsible drinking among college students who binge drink: A multi-theory model (MTM) approach. J. Am. Osteopath. Assoc. 2018, 118, 519-530. [CrossRef]

37. Sharma, M.; Stephens, P.M.; Nahar, V.K.; Catalano, H.P.; Lingam, V.; Ford, M.A. Using multi-theory model to predict initiation and sustenance of fruit and vegetable consumption among college students. J. Am. Osteopath. Assoc. 2018, 118, 507-517. [CrossRef]

38. Hayes, T.; Sharma, M.; Shahbazi, M.; Sung, J.H.; Bennett, R.; Reese-Smith, J. The evaluation of a fourth-generation multi-theory model (MTM) based intervention to initiate and sustain physical activity in African American women. Health Promot. Perspect. 2019, 9, 13-23. [CrossRef]

39. Brown, L.; Sharma, M.; Leggett, S.; Sung, J.H.; Bennett, R.L.; Azevedo, M. Efficacy testing of the SAVOR (Sisters Adding Fruits and Vegetables for Optimal Results) intervention among African American women: A randomized controlled trial. Health Promot Perspect. 2020, 10, 270-280. [CrossRef]

40. Bashirian, S.; Barati, M.; Sharma, M.; Abasi, H.; Karami, M. Water pipe smoking reduction in the male adolescent students: An educational intervention using multi-theory model. J. Res. Health Sci. 2019, 19, e00438.

41. Faul, F.; Erdfelder, E.; Lang, A.G.; Buchner, A. G*Power 3: A flexible statistical power analysis program for the social, behavioral and biomedical sciences. Behav. Res. Methods 2007, 39, 175-191. [CrossRef]

42. Cohen, S.; Kamarck, T.; Mermelstein, R. A global measure of perceived stress. J. Health Soc. Behav. 1983, 24, 385-396. [CrossRef] [PubMed]

43. Sharma, M.; Petosa, R.L. Measurement and Evaluation for Health Educators; Jones and Bartlett Learning: Burlington, MA, USA, 2014.

44. Hair, J.F.; Black, W.C.; Babin, B.J.; Anderson, R.E. Multivariate Data Analysis, 7th ed.; Pearson: Harlow, UK, 2014.

45. Romas, J.A.; Sharma, M. Practical Stress Management. A Comprehensive Workbook, 7th ed.; Academic Press: Cambridge, MA, USA, 2017.

46. NatureRx@Cornell. Available online: https://naturerx.cornell.edu/about (accessed on 3 August 2020).

47. Rothman, K.J.; Greenland, S. Causation and causal inference in epidemiology. Am. J. Public Health 2005, 95, S144-S150. [CrossRef] [PubMed]

48. Dekkers, O.M. The long and winding road to causality. Eur. J. Epidemiol. 2019, 34, 533-535. [CrossRef] [PubMed]

(C) 2020 by the authors. Licensee MDPI, Basel, Switzerland. This article is an open access article distributed under the terms and conditions of the Creative Commons Attribution (CC BY) license (http://creativecommons.org/licenses/by/4.0/). 